\title{
Two New Records of the Genus Minniza Simon (Pseudoscorpiones: Olpiidae) from Iran
}

\author{
Mahrad Nassirkhani \\ Entomology Department, Faculty of Agriculture and Natural Resources, \\ Islamic Azad University, Arak branch, Arak \\ greenartificialturfgrass@gmail.com
}

\begin{abstract}
Recent collections of pseudoscorpions in Fars Province-southern Iran resulted two new country records, Minniza gallagheri Mahnert and M. nigrimanus Mahnert. The species are illustrated and also, some notes on the morphometric ranges and the morphological characters of each species are given here.
\end{abstract}

Keywords: Arachnida, pseudoscorpions, new country records, Fars Province, Iran, Oman.

\section{INTRODUCTION}

The genus Minniza Simon, 1881 currently contains 23 species which are mostly distributed in the old world [1] and can be easily identified by the following combination of characters: body large, abdomen long and vermiform, carapace distinctly longer than wide and carapace with two distinct transverse furrows.

Minniza persica persica Beier, 1951, M. persica deminuta Beier, 1951, M. syriaca Beier, 1951 and M. babylonica Beier, 1931 were previously reported from Iran by Beier [2, 3]. Mahnert [4] considered $M$. syriaca as subjective junior synonym of $M$. babyloica. Consequently, M. p. deminuta was regarded as a junior synonym of the species $M$. persica by Nassirkhani \& Shoushtari [5] who have ignored the differences of the relative lengths of the pedipalpal patella and femur proposed by Mahnert [4] to separate M. p. deminuta and M. p. persica.

Two species, M. gallagheri Mahnert 1991 and M. nigrimanus Mahnert, 1991 are here recorded for the first time from Iran. Also, their mensuration and illustrations are given.

\section{Materials AND Methods}

The specimens used in this study were directly collected by hand, preserved in ethanol 70\%, cleared by lactic acid 60\%, and permanently mounted on dished glass microscope slides in Swan's fluid. The specimens which are deposited in the Acarology Laboratory, Islamic Azad University of Arak (IAUA) examined by using an Olympus BH-2 compound microscope, measured with an ocular graticule, and illustrated with the aid of a drawing tube attachment. Morphological terminology and mensuration follow Chamberlin [6] and Harvey [7]. 


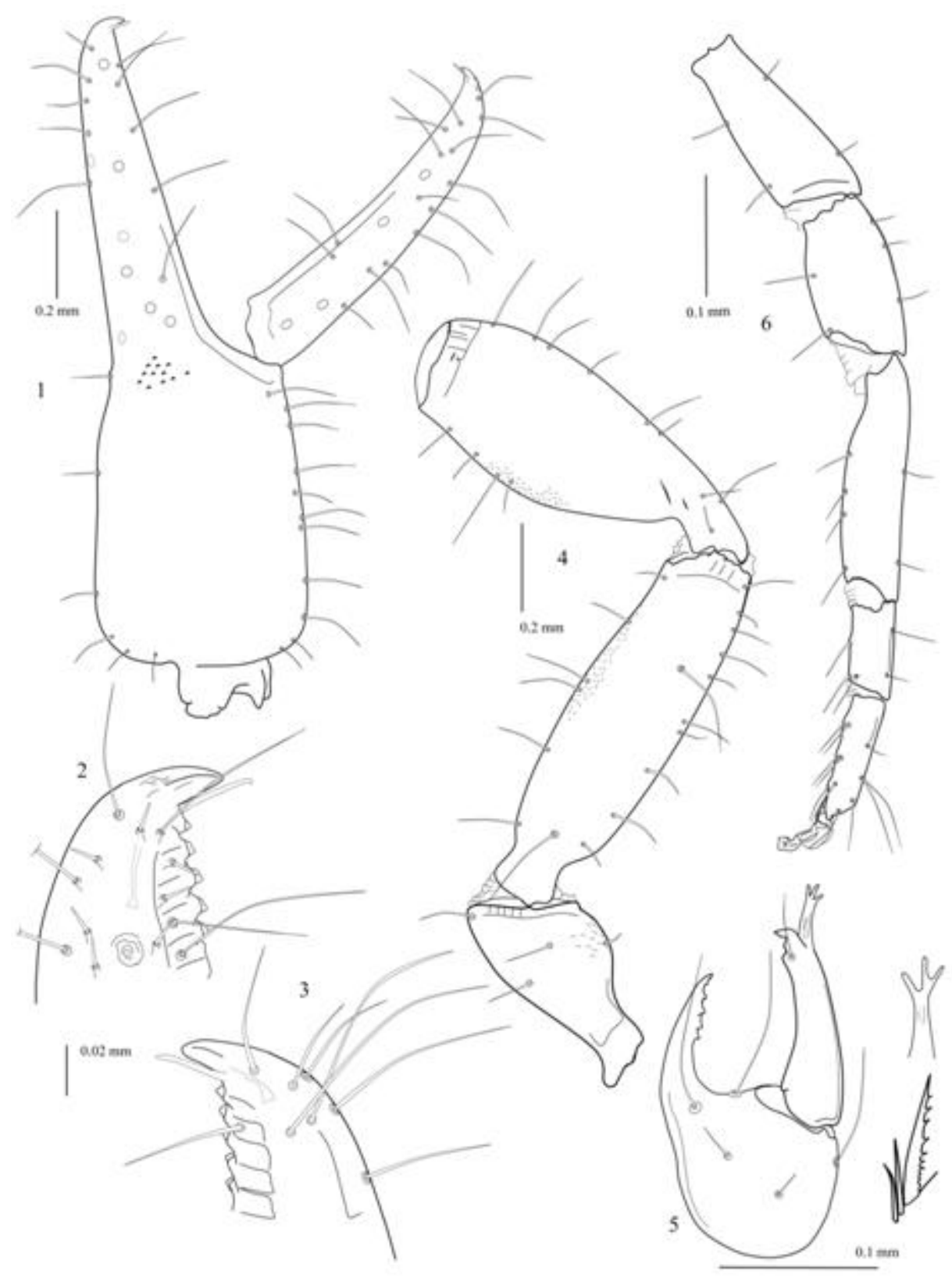

Figures1-6. Minniza gallagheri Mahnert 1991, ․ 1. right chela, lateral aspect; 2. tip of fixed chelal finger (showing venom apparatus and a number of sensory setae); 3. tip of movable finger (showing venom apparatus); 4. basal segments of pedipalp, dorsal aspect; 5. chelicera, galea and rallum (serrulae omitted), dorsal aspect; 6. leg I (trochanter omitted).

Minniza gallagheri Mahnert, 1991: 181-182, figs 30-32.

Family Olpiidae Banks, 1895

Subfamily Olpiinae Banks, 1895

Genus Minniza Simon, 1881

Minniza gallagheri Mahnert 1991

\section{MATERial EXAMined}

IRAN: Fars Province: 1q, Seyyedan [altitude 2010 m], mountain habitat, under stone, July 82014 , M. Nassirkhani (IAUA).

Dimensions in mm: Carapace: $1.13 / 0.60$. Pedipalp: trochanter $0.50 / 0.23$; femur $0.89 / 0.25$; patella 0.85/0.31; chela (with pedicel) 1.50/0.45; chela (without pedicel) L. 1.40; hand (with pedicel) L.0.73; movable finger L. 0.79. Leg $I$ : trochanter $0.15 / 0.15$; femur $0.33 / 0.13$; patella $0.26 / 0.14$; tibia 
0.38/0.09; metatarsus $0.14 / 0.06$; tarsus $0.17 / 0.05$. Leg $I V$ : trochanter $0.22 / 0.17$; femur $0.21 / 0.13$; patella $0.65 / 0.23$; femur + patella 0.77 ; tibia $0.57 / 0.12$; metatarsus $0.21 / 0.08$; tarsus $0.24 / 0.06$.

\section{RESUlts AND DisCuSSION}

Minniza gallagheri Mahnert, 1991, which was previously only known from Oman [1], is here reported for the first time from Iran. A number of differences can be noted between the original description and the Iranian specimen, but they are not sufficient for recognizing a new species. The specimen from Iran is slightly stouter than the types, e.g. in the latter, the pedipalpal femur ratio is 3.90-4.30x, patella 3.00-3.30x, and chela (with pedicel) 3.80-4.20x [4], whereas those of the Iranian specimen are 3.56x, 2.74x, and 3.34x respectively.

Additionally, there are 29-32 cusped teeth on the fixed chelal finger of the types, while the Iranian specimen bears 37. Another observable difference is found in the position of trichobothrium isb on the fixed chelal finger, which is located closer to $e s b$ than to ist in the types (judging from Mahnert [4]: Figs 31-32), but slightly closer to ist than to $e s b$ in the Iranian specimen (Fig. 1).



Figures7-12. Minniza nigrimanus Mahnert, 1991, đ: 7. left chela, lateral aspect; 8. right chela, dorsal aspect; 9. chelal teeth; 10. basal segments of pedipalp, dorsal aspect; 11. chelicera, galea and rallum (serrula exterior omitted); 12. leg I (trochanter omitted).

Minniza nigrimanus Mahnert, 1991: 182-183, figs 33-36.

\section{MATERial EXAMined}

IRAN: Kerman Province: $10^{\lambda}$, Anar [30 $52^{\prime} 57^{\prime \prime} \mathrm{N}, 55^{\circ} 18^{\prime} 43^{\prime \prime} \mathrm{E}$, altitude $1400 \mathrm{~m}$ ], leaf litter, April 26 2015, M. Nassirkhani (IAUA). 
Dimensions in mm: Carapace: $0.87 / 0.52$. Pedipalp: trochanter $0.39 / 0.20$; femur $0.66 / 0.21$; patella 0.65/0.26; chela (with pedicel) 1.15/0.42; chela (without pedicel) L. 1.05; hand (with pedicel) L.0.60; movable finger L. 0.60. Leg I: femur $0.26 / 0.10$; patella $0.21 / 0.11$; tibia $0.30 / 0.08$; metatarsus 0.12/0.05; tarsus 0.14/0.04 Leg IV: femur 0.17/0.11; patella $0.54 / 0.19$; femur + patella 0.62 ; tibia $0.46 / 0.11$; metatarsus $0.17 / 0.07$; tarsus $0.18 / 0.06$.

\section{RESUlT AND DISCUSSION}

Minniza nigrimanus Mahnert, 1991 which was originally reported from Oman by Mahnert [4], is here recorded from Iran for the first time. The Iranian specimen possesses 33 cusped teeth on the fixed chelal finger (29-32 in the types) and 27 (24-25 in the types) on the movable finger. The carapace of the specimen from Iran bears 20 setae (4:4:4:4:4), whereas the types have 4:6:4:4:4. The chela of the Iranian specimen is stouter than that of the types of M. nigrimanus from Oman, e.g. the chela (with pedicel) is $2.74 \mathrm{x}$ longer than broad, as opposed to3.00-3.20x in the types. Also, Iranian specimen has the movable chelal finger as long as the hand (with pedicel), whereas it is longer than the hand (with pedicel) in the types [4].

Based on the shape and coloration of the chela, which are used for separating M. nigrimanus from M. babylonica and considering the range morphometric variation in the species, the male from Iran is attributed to M. nigrimanus.

\section{CONFLICT OF INTEREST STATEMENT}

The author declares that he has no competing interest and has not a financial relationship with the organization that sponsored the research.

\section{ACKNOWLEDGMENT}

The author wishes to thank Dr. Reza Vafai Shoushtari for his advice and Mr. Mahmoud Nassirkhani for his assistance.

\section{REFERENCES}

[1] Harvey M.S., Pseudoscorpions of the World, version 3.00, Western Australian Museum, (2013). Available at: http://museum.wa.gov.au/catalogues-beta/pseudoscorpions [accessed 26 April 2016].

[2] Beier M., Ergebnisse der österreichischen Iran-Expedition 1949/50, Pseudoscorpione und Mantiden. Der Annalen des Naturhistorischen Museums in Wien, 58, 96-101 (1951).

[3] Beier M., Pseudoscorpione aus dem Iran, Der Annalen des Naturhistorischen Museums in Wien, 75, 357-366 (1971).

[4] Mahnert V., Pseudoscorpions (Arachnida) from the Arabian Peninsula. Fauna of Saudi Arabia 12, 171-199 (1991).

[5] Nassirkhani M. and Vafai Shoushtari R., Redescription and remarks on the species Minniza persica (Pseusoscor-piones: Olpiidae) from Iran. Zoology in the Middle East 60, 272-277 (2014).

[6] Chamberlin J.C.,The arachnid order Chelonethida,Stanford University Publications, Biological Sciences, 7(1), 1-284 (1931).

[7] Harvey M.S., The phylogeny and classification of the Pseudoscorpionida (Chelicerata: Arachnida), Invertebrate Taxonomy, 6, 1373-1435 (1992). 